\title{
HET VLIEGVELD PARAMARIBO
}

\author{
L. C. PREIJ
}

Met groote vreugde zal in Suriname en ook in belangstellende kringen in Holland het bericht zijn vernomen, dat de Regeering besloten heeft de fondsen beschikbaar te stellen voor den aanleg van een modern vliegveld te Paramaribo. De verrassing zal des te grooter zijn geweest, omdat deze beslissing is gevallen in dezen tijd, nu zoo geweldige offers voor de militaire en economische defensie des Lands moeten worden gebracht en dus de vrees hier en daar was opgekomen, dat de hangende plannen tot betere tijden in portefeuille zouden moeten worden gehouden.

Dat dit niet het geval is geweest, bewijst van hoe groote waarde het zoowel door het moederland als door dit overzeesche gewest wordt geacht te Paramaribo de gelegenheid te scheppen in de naaste toekomst ook in het intercontinentale luchtverkeer te worden opgenomen.

Toen in den nacht van 14 op 15 December 1934 de Snip zou vertrekken voor een pioniersvlucht naar Paramaribo, heb ik in de Nieuwe Rotterdamsche Courant alle belangstellenden opgeroepen daarbij tegenwoordig te zijn, „opdat hun aanwezigheid zal getui„gen van hun medeleven met dezen tocht, die de oorsprong kan „zijn van de totstandkoming van nationaal luchtverkeer naar en „,in ons Westindisch territoir”.

Nagenoeg vijf jaren later is de tweede stap in deze richting gezet met de beslissing, die Paramaribo een modern vliegveld zal bezorgen.

De termijn was lang, we oefenen daarop geen critiek uit, maar we mogen de hoop uitspreken, dat de volgende stappen in sneller tempo zullen worden gedaan.

Deze volgende stappen zijn: het openen van de mogelijkheid voor de K.L.M., na het gereedkomen van het landingsterrein, haar dienst van Amsterdam naar Paramaribo aan te vangen, het in Suriname zelf tot exploitatie brengen van dit derde verkeersmiddel tot bevordering van de ontwikkeling des lands en ten slotte 
het geven van een opdracht aan onze luchtverkeersmaatschappij de kaart des lands, althans het noordelijke deel daarvan, langs fotogrammetrischen weg te verbeteren, ter verkrijging van exacte gegevens, die onontbeerlijk zijn bij het ontwerpen van plannen, die de ontwikkeling des lands beoogen.

Het luchtverkeer in en rondom het andere deel van ons Westindisch gebied is reeds eenigen tijd in exploitatie. Op 19 Januari 1935 werd de eerste geregelde dienst geopend van Curaçao naar Aruba, op 5 September 1939 kwam het eerste vliegtuig van den geregelden dienst Curaçao-Paramaribo in deze laatste plaats op het tijdelijke landingsterrein Zanderij — aan. Hiermede zal de verbinding Curaçao-Suriname, die per boot 5 á 7 dagen in beslag neemt, op den duur tot 7 uren worden teruggebracht.

De beteekenis van deze lijn voor het onderlinge contact tusschen deze beide gewesten en voor het transport van producten van Suriname naar Curaçao (vruchten, bloemen, pluimveee, eieren enz.) moet niet worden onderschat. Wel bestond er reeds een luchtverbinding tusschen deze beide gewesten, tot stand gebracht door de Pan American Airways, doch deze verbinding duurt langer en de passage-kosten zijn hooger.

De gestadige groei van de met laatstgenoemde lijn, van hare opening af, vervoerde pakketpost, blijkt uit onderstaande cijfers:

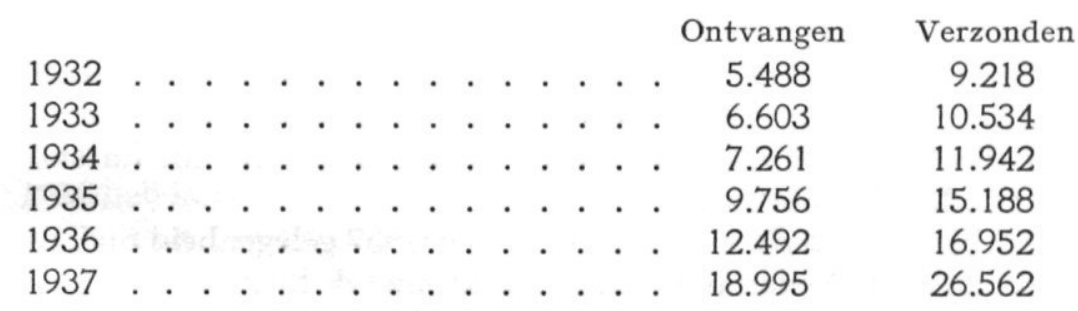

Vanzelfsprekend zal de K.L.M.verbinding tusschen beide Gewesten, na de tot standkoming der luchtlijn Amsterdam-Paramaribo, nog veel belangrijker worden, omdat dan het West-Indische net der K.L.M. als voedingsnet voor deze transatlantische verbinding dienst doet en het transitovervoer tusschen Europa en Midden-Amerika langs de verbinding Paramaribo-Curaçao geleid zal worden.

Dit deel van het luchtnet in onze W.I.gewesten is dus verzorgd; het bedrijf, waarvan Curaçao de basis is, gaat goed vooruit en uit de verbinding met Suriname zullen, dat staat vast, zoovele directe en indirecte voordeelen voortvloeien, dat de steun, die daaraan 
aanvankelijk wordt gegeven, een volkomen gemotiveerde uitgave zal blijken te zijn.

Het te Paramaribo aan te leggen moderne landingsterrein is echter niet bestemd ter verleening van meer faciliteiten aan dezen dienst alleen, maar ontleent vooral aan de in het plan liggende transatlantische verbinding tusschen het Moederland en Suriname zijn groote waarde.

We mogen aannemen, dat het de bedoeling der Regeering is, in de naaste toekomst de K.L.M. in staat te stellen deze verbinding te openen en te verzorgen.

Uit het besluit tot den aanleg van het landingsterrein vloeit dit voort.

Dan zal Suriname in $2^{1} / 2$ dag, Curaçao in 3 dagen van Holland uit bereikbaar zijn.

Niemand zal verwachten, dat deze verbinding, die overigens niet te exclusief als een verbinding Nederland-Nederlandsche overzeesche gewesten moet worden beschouwd, reeds spoedig een rendabele verbinding zal zijn. Dat was ook de Indië-route niet en toch zal de groote nationale beteekenis dezer lijn door niemand meer worden ontkend.

Ik schreef, dat de lijn Nederland-Suriname niet te exclusief als een Nederlandsch belang moet worden bezien, immers zij vormt tevens een verbinding tusschen Engeland en Britsch Guyana en tusschen Frankrijk en Fransch Guyana, terwijl voorts landen als Venezuela, Colombia, de Britsche eilanden Trinidad en Barbados van deze lijn zullen kunnen gebruik maken, zoodat dus de belangen, die bij deze lijn zijn betrokken, verder reiken dan uitsluitend die van het Moederland.

Er bestaat reeds sedert 1 December 1937 gelegenheid mail te verzenden van Nederland naar Suriname met de diensten Duitschland-Zuid-Amerika en Frankrijk-Zuid-Amerika en de daarop te Natal (Noordoostpunt Zuid-Amerika) aansluitende luchtverbinding van de Pan American Airways naar Suriname. Met den Duitschen luchtdienst duurt de overtocht naar Paramaribo 5 dagen, naar Curaçao 6 dagen, met den Franschen dienst 1 tot 3 dagen langer. Het luchtrecht, boven het gewone porto, bedraagt voor Suriname en Curaçao $f 0.50$ per 5 gram.

Ingaande 1 Augustus 1939 is voorts te Paramaribo de gelegenheid opengesteld luchtmail te verzenden naar Europa via Miami, New-York en verder per vliegtuig van de Transatlantic Airmail Service, door tusschenkomst van de N.-Amerikaansche post- 
administratie. Het luchtrecht voor poststukken van 5 gram of gedeelten daarvan bedraagt naar Nederland $f 0.57^{1} / 2$.

Terwijl een normale brief van 20 gram van en naar West-Indië dus thans nog $f 2.00$ á $f 2.30$ kost, vervoert de K.L.M. een brief van gelijk gewicht naar Oost-Indië voor $f 0.25$.

$\mathrm{Nu}$ zal in den aanvang de West-Indische verbinding met hare tarieven niet aan die naar Oost-Indië gelijk kunnen zijn, maar het is toch wel belangwekkend bovenstaande cijfers naast elkaar te stellen.

Stond men in Suriname tot nog voor betrekkelijk korten tijd sceptisch tegenover de beteekenis van het vliegtuig voor diensten in het land zelf, dit gevoelen heeft in den laatsten tijd een zeer belangrijke verandering ondergaan.

Men kan gelukkig constateeren, dat thans algemeen het gemis van luchtverbindingen boven Surinaamsch grondgebied wordt erkend. De ervaring, opgedaan bij de vluchten uitgevoerd door een vlieger uit Britsch Guyana in samenwerking met de grensafbakeningsexpeditie, voorts die welke zijn uitgevoerd ten behoeve van den exploratie-arbeid der concessionarrisen van de Compagnie des mines d'or in het Lawa-gebied en ten slotte de vlucht, die nog onlangs heeft geleid tot het vaststellen van nog onbekende savanes in het centrum des Lands, die vermoedelijk als landingsterrein en dus voor verdere uitbreiding van het plaatselijk net te zijner tijd van belang zullen blijken te zijn, hebben er niet weinig toe bijgedragen, dat men thans ter plaatse aan dit derde verkeersmiddel groote waarde is gaan hechten.

In De West-Indische Gids van Januari 1934 en in die van Mei 1938 heb ik gewezen op de verschillende objecten, welker ontwikkeling kan worden bevorderd, zoodra verkeer door de lucht in Suriname mogelijk zal zijn. Zeer gedocumenteerd en uitgebreid is op de vele mogelijkheden in dit opzicht gewezen door Dr. Ir. W. C. Klein, in de Indische Gids, Februari-aflevering 1939.

Op twee punten wil ik nog eens in het bijzonder de aandacht vestigen, omdat de latere ervaringen hebben aangetoond, dat de met het vliegtuig te bereiken resultaten veel belangrijker kunnen zijn dan destijds werd verondersteld.

Dit betreft in de eerste plaats de mogelijkheid tot het verkrijgen van meer gegevens omtrent de geologische gesteldheid des lands.

Het is gebleken, dat in dit opzicht de luchtfotografie zeer waardevolle gegevens verschaffen kan.

Men heeft in Suriname jarenlang aangedrongen op het wederinstellen van een geologischen exploratie- en voorlichtingsdienst. 
Steeds weder zijn de voorstellen daartoe moeten worden afgewezen, omdat de daaraan verbonden kosten zeer hoog zouden moeten worden gesteld, wilde men daarvan eenig nut verwachten.

De luchtverkenning kan in dit opzicht tot belangrijke kostenbesparing leiden, omdat zij gegevens verschaffen kan omtrent de streken, waar nadere grondverkenning gewenscht moet worden geacht en loonend zal kunnen zijn. $Z \mathrm{ij}$ zal dus hen, die zich voor exploratie-arbeid interesseeren (een gouvernementsgeologischen dienst dan wel particuliere ondernemers) als het ware kunnen leiden naar die gebieden, waar de kansen op het bereiken van resultaat vermoedelijk aanwezig zullen zijn. Voor een goud- en bauxiethoudend land, waar bovendien indicaties van petroleum, diamant en cinnabar zijn aangetroffen, is voor het vliegtuig, aldus aangewend, zeker een arbeidsveld aanwezig.

De andere kwestie, waarvoor in den laatsten tijd het vliegtuig heeft bewezen van groote beteekenis te kunnen zijn, in het bijzonder voor tropische gewesten, is het bestuiven van cultures ter bestrijding van schadelijke insecten.

Te dien aanzien zijn er in Juli 1938 uitgebreide proeven genomen op het vliegveld Ypenburg. De heeren Ir. J. J. Franssen, entomoloog van de Commissie inzake bestudeering en bestrijding van insectenplagen in bosschen, (waarin ook de Nederl. Heidemaatschappij is vertegenwoordigd) en D. A. C. Schoevers, phytopatholoog van den plantenziektenkundigen dienst, woonden deze demonstraties bij.

De proeven hebben de gemakkelijke uitvoerbaarheid der methode aangetoond, terwijl uit de reeds ter beschikking staande gegevens omtrent de toepassing in andere landen (Duitschland, Vereenigde Staten) is gebleken, dat de kosten betrekkelijk laag en voor de cultuur geenszins ondragelijk zijn.

Naar mijn meening kan de waarde van deze methode voor het gezond houden der cultures, hetgeen in Suriname een zaak van voortdurende zorg is, bezwaarlijk te hoog worden aangeslagen.

Ten slotte nog een woord over de cartografie.

Ook ten aanzien hiervan heeft men thans in Suriname het scepticisme laten varen. Langen tijd is men van oordeel geweest, dat de daaraan te besteden kosten niet rendabel kunnen worden geacht en dat het daaraan toe te kennen belang in ieder geval moet worden achtergesteld bij verschillende andere nooden, waarin moet worden voorzien.

Daartegenover ben ik steeds van meening geweest, dat het een 
eerste behoefte voor de ontwikkeling des Lands is, het geografisch zoowel als topografisch te "kennen” en dat is tot nu toe niet het geval.

De kaart van het land, met de vele blanco plekken, is daartoe het meest overtuigende bewijsstuk en men moet daarbij dan nog in aanmerking nemen, dat van hetgeen er wel op voorkomt, de absolute juistheid niet vaststaat.

De belangstelling voor dit vraagstuk is echter, gelukkig, zeer toenemend. Zoowel in de Volksvertegenwoordiging bij de behandeling der Surinaamsche begrooting, in tijdschrift- of dagbladartikelen als nu ten slotte ook in Suriname zelf, wordt aan het gebruik van het vliegtuig voor dit doel aandacht geschonken. Het Gouvernement heeft hiermede reeds een begin gemaakt door, in aansluiting aan het cartografische werk, dat de K.L.M. te verrichten kreeg voor de daar te lande exploreerende Billiton Maatschappij, eenige verkenningsopdrachten te geven.

Er ligt hier een beteekenisvolle taak voor de fotografische afdeeling van de K.L.M., die, naar wij zeer hopen, daartoe door de Regeering, zoodra de grondorganisatie te Paramaribo gereed zal zijn, zal worden in staat gesteld.

Verschillende methoden zijn in den loop des tijds voorgesteld.

Men kan zich, om der kosten wille, aanvankelijk beperken tot het in kaart brengen van stroken langs de Commewyne, Suriname, Saramacca en Coppename, met de bedoeling in de eerste plaats te geraken tot een juiste plaatsbepaling van den loop dezer rivieren, althans over een gedeelte hunner lengte en tevens een juist beeld te krijgen van de aangrenzende terreinen, waarin veelal concessies van allerlei aard zijn gelegen en exploratie-vergunningen worden uitgegeven.

Men kan zich, eveneens om der wille van de kosten, beperken tot het in beeld brengen van bepaalde landstreken, die, hetzij voor de boschexploitatie dan wel voor aanleg van wegen of voor ontginning en irrigatie, ten behoeve van den landbouw, van primair belang moeten worden geacht. Een plan in dezen zin treft men aan in de bovenaangehaalde studie van Ir. Klein.

Ten slotte kan men systematisch de kaart van het geheele land verbeteren door, aanvankelijk het noordelijk, daarna het middenen ten slotte het zuidelijk deel te fotografeeren.

Deze methode is oogenschijnlijk de kostbaarste.

$\mathrm{Zij}$ is echter, naar mijn meening, de doelmatigste.

Het partieel opnemen van deelen des lands, zonder onderling verband, is voor de verbetering van de kaart de minst practische 
methode, omdat het later daarop aansluitend kaartwerk groote moeilijkheden zal veroorzaken en leiden zal tot ontolereerbare fouten.

Zou men zich tot het opnemen van terreindeelen, als in de beide eerstaangegeven methoden bedoeld, kunnen beperken, dan zouden zij zijn te overwegen. Waar echter verbetering van de geheele kaart des lands een werk is, waartoe men in het belang van zijn ontwikkeling toch zal moeten komen, is het n.m.m. veel doelmatiger van den aanvang af en systematisch zich op deze algeheele opname voor te bereiden en dus in het Noorden beginnend, over een strook van een bepaalde afmeting, daaraan als tweede en derde etappe een opname van het midden en zuiden des lands te doen aansluiten.

Een destijds door de K.L.M. opgemaakt plan tot luchtfotografische opname van de noordelijke helft des lands, een werk, dat in $2^{1} / 2$ jaar zou kunnen worden voltooid, zou een uitgave vorderen van $f 480.000$ voor het eerste en tweede jaar en van $f 240.000$ voor het derde jaar.

Deze begrooting betrof de uitvoering van een op zichzelf staande opdracht in een tijd, waarin er in Suriname op luchtvaartgebied nog niets bestond en dus alles uit Holland en Curaçao moest worden aangevoerd. Het spreekt van zelf, dat de kosten lager zullen zijn, indien het landingsterrein te Paramaribo gereed zal zijn en de organisatie, met het oog op den dienst op het Moederland, zal zijn tot stand gekomen.

Het belang, dat voor de ontwikkeling des lands gelegen is in het bezit van een exacte kaart, is echter zóó groot en het daartoe gedurende $2 \frac{1}{2}$ jaar ter beschikking te stellen bedrag naar verhouding zóó matig, dat voor het tot nu toe uitblijven van een opdracht aan onze luchtvaartmaatschappij moeilijk een andere verklaring is te vinden dan deze, dat nieuwe zaken altijd eenigen tijd moeten hebben om algemeene waardeering te kunnen vinden.

We mogen echter hopen, dat de tijd, waarin dit Nederlandsche gewest in Zuid-Amerika voor de oogen der wereld er, na een bewindsperiode van bijna 125 jaren, in kaartvorm nog uitziet als een grootendeels onbekend land, weldra tot het verleden zal behooren. 